\title{
Zufallsbefund Milzzysten
}

\section{Wie hoch ist das Rupturrisiko?}

Frage von Dr. med. N. E.:

Eine sportliche 30-jährige Patientin sprach mich an, inwieweit bei ihr zufällig diagnostizierte Milzzysten (6 x $6 \mathrm{~cm}$ und 3,5 x $4 \mathrm{~cm}$ ) bei körperlicher Aktivität oder auch bei Unfällen komplikationsträchtig rupturieren könnten. Sie wollte wissen, ob ein präventive Entfernung/Punktion nicht sinnvoll wäre. Gibt es Daten zur Häufigkeit und zu Komplikationen solcher Rupturen?

\section{Antwort von Dr. med. Martin Held, München:}

Es ist zu unterscheiden, ob die Zysten an der Oberfläche der Milz sind oder von Milzgewebe umgeben. Letztere sind ungefährlich. Ferner sollte erwiesen sein, dass es sich um eine blande Zyste handelt und nicht um eine eingeblutete Zyste.

Ich würde die Zysten auf Größenzunahme kontrollieren und bei Größenzunahme die Zystenresektion, nicht die Splenektomie empfehlen. Die Spontanrupturrate ist sehr gering und bei ober-

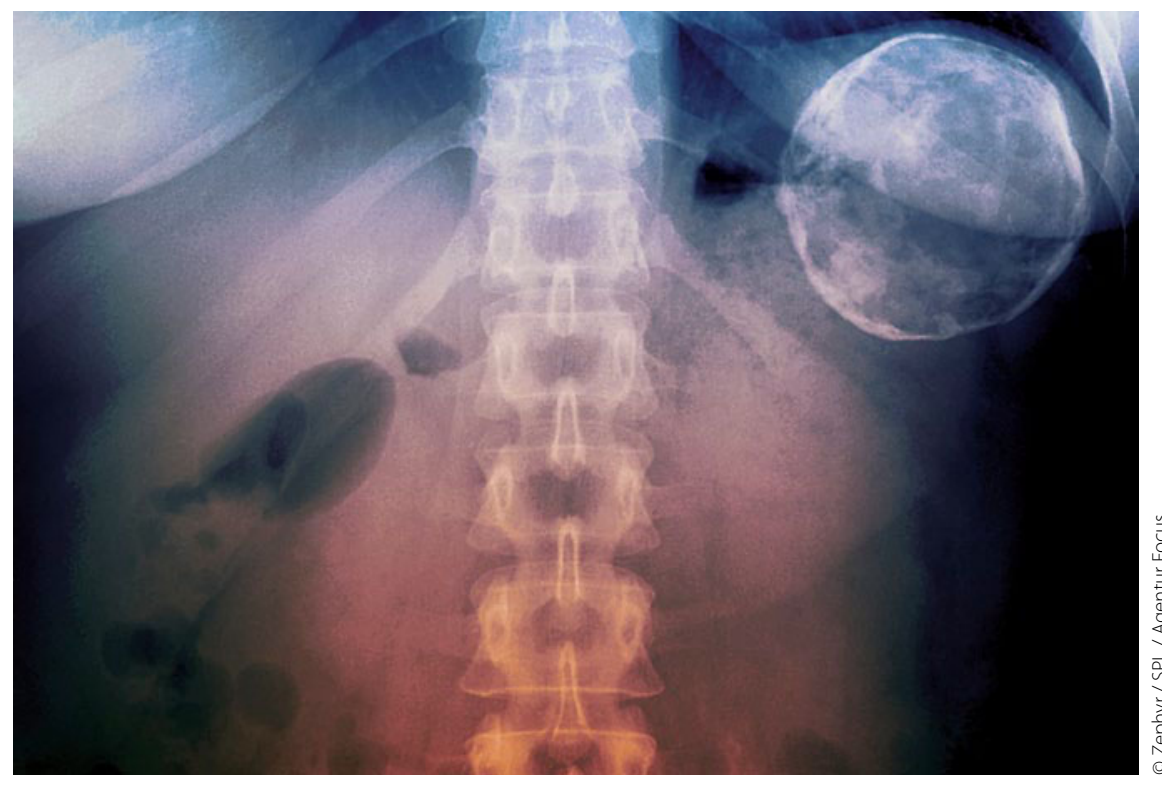

Milzzyste: punktieren, operieren oder abwarten?

flächlichen Zysten sicher unter 5\%. Natürlich kann ein Trauma zu einer Ruptur führen aber ebenso zu einer Milzruptur.

Eine Punktion ist nicht sinnvoll, sondern wegen der Blutungsgefahr eher ri- sikoreich. Aktuell halte ich eine abwartende Haltung für gerechtfertigt.

- Dr. med. Martin Held, Facharzt für Innere Medizin und Gastroenterologie, Isartorplatz 4, D-80331 München

\section{Hämochromatose nach Chemotherapie}

\section{Gibt es da eine Therapieempfehlung?}

\section{Frage von Dr. I. K.:}

Ein Patient hat eine Hämochromatose mit einem Ferritin über $1000 \mu \mathrm{g} / \mathrm{l}$ nach Chemotherapie. Gibt es eine Therapieempfehlung?

Antwort von Prof. Dr. med. H. Link, Kaiserslautern:

Eine Hämochromatose ist eine angeborene genetische Erkrankung mit verstärkter Eisenaufnahme. Bisher sind fünf ver- schiedene Varianten bekannt. Diese Genmutation ist nicht durch Chemotherapie auslösbar.

Sie meinen wahrscheinlich einen Ferritinanstieg bei Leukämie, Lymphom oder Karzinom. Dieser Ferritinanstieg ist durch das Malignom bedingt, sofern nicht viele Erythrozytentransfusionen erfolgt sind. Ferritin ist auch ein AkutePhase-Protein, das in der Dünndarmschleimhaut sowie in den Zellen des
Knochenmarks, der Milz und der Leber gebildet wird. Es steigt bei Entzündungen und Aktivierung des Immunsystems an. Werte über $1000 \mathrm{ng} / \mathrm{ml}$ kommen durchaus vor und müssen nicht behandelt werden.

- Prof. Dr. med. Hartmut Link, Chefarzt der Medizinischen Klinik I - Hämatologie, Internistische Onkologie und Endokrinologie, WestpfalzKlinikum, Hellmut-Hartert-Straße 1, D-67655 Kaiserslautern 